\title{
An Integrating Model for Excellence: Mentorship to Enrich the Three Pillars of Education
}

\author{
S. Hallman ${ }^{1}$, L. Massoud ${ }^{2}$ and D. Tomiuk ${ }^{3}$ \\ ${ }^{1}$ Executive Faculty - Cyber Security, School of Computer and Information Sciences \\ University of the Cumberlands, Williamsburg, KY, USA \\ ${ }^{2}$ IT Department, Computer Information Systems Program, Mott Community College, \\ Flint, MI, USA \\ ${ }^{3}$ Tenured Professor, Department of Management and Technology, University of Quebec in \\ Montreal, Canada
}

Correspondence should be addressed to: D. Tomiuk; tomiuk.daniel@uqam.ca

Received date:10 September 2019; Accepted date: 4 April 2020; Published date: $1^{\text {st }}$ September 2020

Academic Editor: Nasrin Shah AbuShakra

Copyright (C) 2020. S. Hallman, L. Massoud and D. Tomiuk. Distributed under Creative Commons Attribution 4.0 International CC-BY 4.0

\begin{abstract}
How does one progress from protégé to professional to master? For thousands of years, it was accomplished by apprenticeship to a master, on a one-to-one or one-to-few basis. The advent of the industrial era necessitated training more people at a time than this model could accommodate; hence, the modern educational era. The traditional classroom model and coaching became standard. The disadvantage of this model, however, is that the nuance of the "master" is lost because it can only develop over a long-term, individual, guided, mentoring relationship. Although our institutions of higher learning successfully develop accomplished professionals with their three-tiered model of teaching, service, and research, these authors propose moving educators closer to the "master" level of skill by reincorporating the individual mentorship model in conjunction with small cohort coaching.
\end{abstract}

Keywords: education, mentoring, coaching, faculty, cohort

Cite this Article as: S. Hallman, L. Massoud and D. Tomiuk (2020)," An Integrating Model for Excellence: Mentorship to Enrich the Three Pillars of Education", Journal of e-Learning and Higher Education, Vol. 2020 (2020), Article ID 645632, DOI: 10.5171/2020.645632 


\section{The Early Beginnings}

For thousands of years, the way to transfer technical, skilled, or artisan knowledge to the next generation was by means of one-toone apprenticeship programs. The novice would be apprenticed to the master and would spend years living and working with the master until he/she gained the requisite level of knowledge and skill. Under this system, the novice not only learned the technical knowledge and skill, but also the behaviors, attitudes, and personality traits needed by a master.

Formal classroom training became a way to train a larger number of people at the same time. While technical knowledge, and some level of skill, can be transmitted by this method, it does not result in the level of "craftsmanship" achieved by years in the continuous presence of the master. Many professional occupations have used the classroom model in attempting to achieve artisan-level skills but have found it to be inadequate and have modified training methods to increase time and decrease apprentice group size. There are many examples of formal mentoring programs in a variety of occupations. The American Osteopathic Association now requires an osteopathic doctor residency (Burkhart, 2008; Pinilla et al, 2015). Nursing is another area in which mentorship has been incorporated into training outcomes (Williams et al, 2018). The legal field is calling for mandatory mentorship or internship for new attorneys (Mentoring Program Will Help New Lawyers Go Solo, 2013; Payne, 2016; Rhode, 2017; Lewinbuk, 2018-2019). Of course, the military is wellknown for his mentorship training model. (Johnson, 2015; Wenzel 2015). Lack of personal, individual mentorship can result in "adequate" knowledge, but almost certainly not in the "master" (artisan) level of expertise.

Applied to the field of education, Socrates, Plato, and other famous educators effectively transmitted not only their knowledge but also their thinking and reasoning processes to students via the method of extremely small group mentorship conducted over multiple years.
The goal of this paper is to evaluate the possible roles of both coaching and mentoring as applied to educational institutions.

\section{Three-Pillared Model: Teaching, Service, Research/Publication}

Educational institutions have adopted the three-pillared model of teaching, service, and research/publication as hallmarks of "success" as an educator. More than most other occupations, the "education" field anticipates and expects a significant dedication to "mentoring" in many forms and definitions. As a visitor at many educational institutions over multiple decades, one author has observed a set of approaches that can contribute greatly to the "maturity" of the institution's mentoring component, at all levels of education.

\section{Typical Faculty Rank Progression}

Typically, a junior faculty member (instructor or assistant professor) will become involved and seek an understanding of how the institution's internal policies and processes work. After a certain period (approximately a term/semester), when they are encouraged or when the junior faculty member gets their feet on the ground, their direct report person (Program Coordinator/Chair) typically gives their "blessing" to increase their activity and service under the watchful eye of their supervisor and/or mentor. Hence, the process of coaching and mentoring begins. More and more institutions are implementing formal newhire cohort coaching programs to smooth the assimilation process.

As time progresses, the faculty member feels more comfortable in performing their daily operational activities, leading to richer engagement in teaching style, overall service, and research duties (typically in this order for teaching schools). It is also common to see the new faculty's internal drive of learning and performance continue to flourish. This is where having appropriate mentoring environment can enable the faculty member to cultivate their career into that of a professional educator. 
Mentoring from both a seasoned peer(s) and from supervisory management are vital to guiding new faculty through the maze of educational bureaucracy and assessment.

\section{Pillar \#1: Teaching}

For most teaching schools, having faculty members engaged in teaching is paramount. Effective teaching comes first and carries the most weight on faculty performance reviews. Therefore, the question becomes: how do young faculty members develop teaching skills and receive fair 360 degreefeedback reviews from their key internal and external stakeholders?

\section{Vertical and Lateral Relationships}

Teaching should occur not only in the classroom, in a vertical relationship with students, but should also occur laterally, in relationships with other educators. Many colleges are instituting formalized multiyear cohort training for new-hires (Reddick, 2015). Training includes an introduction to the educational environment and the expectations associated with teaching, such as learning theory, teaching theory, philosophy of the university (or community college, as appropriate), technology skills, and relationship skills. Building a community out of these new-hires can result in a peer mentoring environment that will greatly increase the retention rate after that first, difficult year.

In addition to the cohort coaching environment, which is becoming increasingly common, some schools recognize the importance of pairing new teachers with experienced individual mentors who can guide them through difficult patches. This kind of mentoring should be personalized to the unique individual and should be of adequate duration to develop a trust relationship between the two. Articles offer specific suggestions on how to approach the creation of a formal mentor relationship. (Starcevich, n.d.) The ideal scenario would be for the institution to facilitate both coaching and mentoring relationships among faculty (as well as other employees).

The lateral mentoring relationship is not only important for new-hire employees but could also be of great value to more longstanding employees. Each person has strengths and weaknesses, and a strong relationship allows the person to be vulnerable in asking for help. It can also promote the development of crossdivisional alliances that benefit students rather than developing isolated silos of knowledge.

\section{Pillar \#2: Service}

At the university level, service is another important weight in faculty assessment and valuation. There is a wider range of service expectations between junior and senior faculty (Associate/Full Prof) members. At the community college level, service is weighted lower during evaluations but is no less important.

Service can be viewed by its focus: downward, inward, upward, and outward.

\section{Downward}

One way to serve is to be a mentor or coach to students. An example would be a club advisor or a participant in a service-learning opportunity. Students learn much from seeing someone in their intended occupation, demonstrate the value of working for and with others. The faculty member gains a broad range of experiences from these relationships.

\section{Inward}

Internal college activities are the second category of service opportunities. It is common to see junior members take part in a wide range of committee service to the university, their assigned college/school, and their own program. Serving on these committees results in dual benefits, not only to the college infrastructure but also to the personal experiential development of the faculty member.

\section{Upward}

The service expectations will widen and deepen with more senior faculty rank. Some senior-level faculty assume a formal/informal role of mentoring the new faculty member for those embarking on the tenure and promotion track. For the new faculty member, engaging with a sideline 
mentor makes for good sense; obtaining his/her insight and overall guidance is a logical step in the right direction. Some institutions have created stipend-funded, cross-divisional mentorships between experienced faculty and new-hires, hoping that heterogeneous grouping will create a synergistic learning effect for both. The mentorship approach may be more effective for this particular activity than a coaching approach since it broadens the faculty member's base of experience.

\section{Outward}

Senior faculty members are frequently engaged in their own professional discipline organizations and have a natural, but earned, ability to flow into leadership committee roles such as director, chair, and/or president of a non-profit organization. For the professional at heart, the service role continues - life long. For some, it may branch into receiving a Fulbright Scholarship or service grant, while others might be interested in future management (director, chair, or dean) role. Still others will start to learn more about advisory committee/council councils, Institutional Review Boards, program accreditation, and online (LMS) models.

For any professional, career-minded faculty member, there is no doubt that having clear expectations, understanding the unwritten rules, and learning the written processes for earning promotion and tenure are important to success. As the member progresses through these service "directions" they gain additional expertise in internal and external leadership. For the service pillar, in particular, a faculty member can benefit from the advice of both a coach who can provide solid process advice (tangible aspects) and a mentor who can share individual knowledge and suggestions (the intangible aspects).

\section{Pillar \#3: Research}

The third pillar of the traditional developmental triad is research (and publication). "Research" can take on various meanings and importance at different types of educational institutions.

\section{University Level}

For the university professor, the "publish or perish" saying exemplifies the tremendous importance placed on research and publication as part of the tenure or renewal process. At that level, professors are expected to be researching in their technical field and/or defining cutting edge enhancements that would improve the entire field. Funding and contributions to the university, which eventually trickle down to the individual professor level, are determined by the quality of the research.

A university program that wishes to be maximally successful would be wise to design and implement a formal coaching program to instruct new professors in the institution's techniques and expectations for research and publication. In addition to that, however, establishing one-on-one mentoring relationships between more experienced and less experienced faculty in the same discipline would lead to earlier and more effective research and publication. A joint effort might also be possible. Even though a group coaching lesson might explain the general policies and procedures, there is no substitute for the practical, individual attention of a seasoned veteran. Both group coaching and individual mentoring are important to engender the kind of seasoned professional that can carry the university into future decades.

\section{Community College Level}

At the community college level, research and publication have not traditionally been highly positioned in determining raises and tenure. The number of classes taught by community college educators significantly reduces the time available for the design, implementation, analysis, and publication of significant experimental research. On the other hand, community college educators have regular access to an extremely heterogeneous group of students. Given the time, interest, and ability, community college professors are uniquely positioned to conduct academic research in fields such as teaching, learning, and methodology. Although such research might not be appropriate for publication in technical journals, there are many educational 
publications that would be suitable for the dissemination of the results of such research. Even if the research will not be a basis for salary and promotion, it would be good for the community college to find a way to acknowledge the contributions of its educators to the field of teaching and learning. The individual mentoring model would also be most suitable for those who wish to pursue this avenue.

\section{Mentor Program Design}

\section{Institutional Level}

Faculty turnover is costly and detrimental to any school or college as it erodes the fiber of longevity and long-term professional accomplishments. (Phillips, 2015) Turnover is a lose-lose situation for the school, the faculty member, and students. The goal should be to have an institutionally-grounded, proactive engagement program offered to new faculty members, encouraging them to seek promotion, tenure, and beyond. This long journey is all about fostering professional growth - while building trust at the same time. Mentoring from a higher-ranking faculty and with periodic review and guidance by management (chair or dean level) are key factors for professional success. It leads to shared responsibilities, vetting, and shared governance. Admittedly, an institutional mentoring program is difficult to achieve because of time and limited resources. It requires a design phase that is long-term and relationship-oriented (The Differences Between Coaching \& Mentoring, n.d.). Nevertheless, by committing to investment in the future, this process commonly leads to reciprocal mentoring agreements, not only by faculty members but at all levels within the school/college. When this proactive mentoring and process evolves, it blossoms into a win-win situation for all stakeholders.

\section{Mentor Level}

Of those who have been the most successful in any area of life, most will quickly name one or more mentors who guided them in their journey. Informal mentoring can occur in a variety of topics, settings, and durations. Formal mentoring is more like a contract where one person will guide another toward a certain objective by inspiring the development of certain behaviors over a specified length of time (Alshamsan, 2015). (Formal mentoring might be more likely as part of an institution's professional development program. One hopes that informal mentorships would also spring up.) Many advanced professionals freely offer their mentoring services -- to those who exhibit the longing. They are gratified to see a new generation of growing professionals, and they are honored that their expertise is sought.

\section{Mentee Level}

The ultimate responsibility for obtaining a mentor, however, lies with the mentee. As the saying goes: "You can lead a horse to water, but you cannot make him drink." The same applies to the mentor-mentee relationship. It is, ultimately, the responsibility of an individual person to perceive and espouse an attitude of wanting to be mentored and then work to put it into effect. Stories of spurned offers to provide mentoring are common and deter many professionals from even offering the service which is why a mentee must take the initiative.

Personal Learning Networks offer the opportunity for a customized online "network" of information and interaction that can accomplish some of the mentoring objectives (Rajagopal et al, 2012). By far the most valuable, though, is to have a local, individual, private relationship with someone of advanced skill in <whatever> area. There is no substitute for absorbing proficiency under the direct, guiding hand of a master. The connection is important, but it is the attitude of the mentee that promotes the greatest achievement in the mentoring relationship (Rajagopal et al, 2012; Czerkawski, 2016).

\section{Recommended Assessment Methods}

Over time, educational management has recognized a wider range of values, assessment methods, and tools to gather faculty performance data throughout the year in order to build a historical baseline of performance. This data later becomes an 
integral part of the employee's promotion and tenure portfolio.

Some schools are performing one or two personal assessments items, while others (particularly those with program accreditation) are more aggressive in data collection activities and incorporate all four of the assessment techniques (listed below) into a 360-degree evaluation (Study Makes the Case for Employee Engagement in Higher Education Institutions, 2016). The intent is to facilitate and professionally mentor (through data collection) the upcoming faculty member.

Four suggested assessment components:

1) Software tools (databases) designed to assess the current classroom environment with data comparisons on peer courses and faculty performance from across the nation in similar institutions. Upon review, the faculty members can see direct feedback from their course and the relationship with similar courses from closely related peer schools/colleges.

2) Program core assessment software/suites, designed to measure "core program competencies" (CPC's), illustrating student-learning outcomes in the core course(s). The course faculty has discussions with other subject/peer faculty members leading to course improvement and enhancements.

3) Faculty classroom or online visits are necessary. These are validation visits, by a subject matter peer, a faculty member outside the department/school, and/or by any member of management. This participation allows for a review and feedback from the perspective of a peer as a subject matter expert (SME) and/or a novice point of view (outside of the subject matter). Having both perspectives, from an SME and novice is important to give the faculty member a well-rounded picture of the student perspective. The findings typically illustrate overall classroom interaction/climate, how knowledge is exchanged/perceived, and the connectivity of the theory to application component. The goal here is to gather teaching methods and performance data from all key stakeholders.
4) Classroom visit by management (chair or dean), allowing firsthand observation on how the faculty member interacts with his/her students, the natural flow of information, Q/A during instructions, formative assessment, and the understanding with the application of knowledge.

\section{Existing Models}

Private industry has found the value in solid mentorship programs, and many are incorporating mentorship as a means of attracting and keeping good talent. Examples include Time Warner Cable, Caterpillar, Intel, General Electric, Deloitte, Boeing, and Liberty Mutual (Simmons, n.d.). Many HR and Career websites contain articles suggesting methods for implementing mentorship programs in a variety of occupational fields (Androitis, 2018). Academia is also promoting the importance of mentoring in higher education (Vance, 2016). A school district incorporates many of these suggestions into their professional development approach (Morrison, 2019).

At one author's college, Mott Community College in Flint, Michigan, all new full-time faculty enter a three-year mentoring program using the cohort model. The program is led by a full-time faculty member and a dean. Faculty meet once a month for group activities. In addition, they do classroom observations to learn a variety of teaching techniques in various divisions. They read and discuss books, work on teaching portfolios, and learn about various college functions. Many have informal mentors within their divisions. (This author is one.) In addition, there is a similar, but condensed, program available for Adjunct faculty that provides a stipend for those completing the training program. A further opportunity provides technology instruction and activities for faculty members who wish to enhance their classroom experiences with more technology. The result is an energetic, enthusiastic, and well-trained cadre of faculty. 


\section{Conclusion}

Unlike the K-12 system where each student works under the tutelage of a supervising teacher, training for new teachers in higher education is directed by the mandates of the individual institution. Teaching, service, and research are quite consistently required, but the methods of helping these nascent professors achieve a high level of skill in these three areas and could be enhanced greatly by the inclusion of targeted mentoring programs, supplemented by the small cohort instruction. Industry is finding that attracting, training, and maintaining valuable employees is well worth the investment. Likewise, as schools are forced to move toward a positive Return on Investment (ROI) model due to limited funding, it will be important to implement cost-effective mentoring programs to attract and retain the most effective educators. Many private schools are already closing, and while there are always multiple factors leading to that result, it is true that the best way to attract more students is to provide the highest quality of education. The best way to achieve that high quality is to create a successful mentoring program. Mentorship must be "embraced by the university and made a part of the institutional fabric" (Kahle-Piasecki, 2015, p. 75) The most successful schools will have a combination of small cohort training for foundational skills, and also an entrenched individual mentoring program to help novices become the seasoned and skilled master "artisan" in the educational arts that will keep our schools viable.

\section{References}

- Alshamsan, A., 2015. Mentoring and Coaching. [Online] Available at:

https://www.linkedin.com/pulse/men toring-coaching-abdulaziz-alshamsan

- $\quad$ Androitis, N., 2018. How to Successfully Implement Your Mentorship Program in the Workplace. [Online] Available at: https://www.efrontlearning.com/blog 2018/08/how-implement-mentoringprogram-in-the-workplace.html
- Anon., 2013. Mentoring Program Will Help New Lawyers Go Solo. Tennessee Bar Journal, 49(12), p. 6.

- Anon., 2016. Study Makes the Case for Employee Engagement in Higher Education Institutions. [Online] Available at: https://www.ellucian.com/News/Stud y-Makes-the-Case-for-EmployeeEngagement-in-Higher-EducationInstitutions/Anon., n.d.. The Differences Between Coaching \& Mentoring. [Online] Available at: http://www.managementmentors.com/resources/coachingmentoring-differences

- $\quad$ Burkhart, D. \&. L. T., 2008. Osteopathic Graduate Medical Education. AOA Communication, March.pp. 127-137.

- Czerkawski, B., 2016. Blending Formal and Informal Learning Networks for Online Learning. The International REview of REsearch in Open and Distributed Learning, 17(3).

- Johnson, W. \&. A. G., 2015. Mentoring in the U.S. Navy. Naval War College Review, 68(3), pp. 76-90.

- Kahle-Piasecki, L. D. S., 2015. A Comparison of Mentoring in Higher Education and Fortune 1000 Companies: Practices to Apply in a Global Context. Journal of Higher Education Theory and Practice, 15(5), pp. 74-79.

- Lewinbuk, K. P., 2018-2019. Kindling the Fire: The Call for Incorporating Mandatory Mentoring Programs for Junior Lawyers and Law Students Nationwide. St. Louis U. L. J., 63(2), pp. 211-234.

- Morrison, M., 2019. Reimagined Staff Development. Education Digest, 84(5), pp. 41-45.

- Payne, W. R., 2016. Mentoring and Sponsorship: Retaining Diverse Attorneys in a Commercial Litigation Practice. Commercial \& Business Litigation, 18(1), pp. 10-13.

S. Hallman, L. Massoud and D. Tomiuk (2020), Journal of e-Learning and Higher Education, DOI: $10.5171 / 2020.645632$ 
- Phillips, 0., 2015. Revolving Door of Teachers Costs Schools Billions Every Year. [Online] Available at:

https://www.npr.org/sections/ed/20 15/03/30/395322012/the-hiddencosts-of-teacher-turnover

- $\quad$ Pinilla, S. P. T. v. d. B. P. F. M. R. \&. D. K., 2015. 5 years of experience with a large-scale mentoring program for medical students.. GMS Zeitschrift Für Medizinische Ausbildung, 32(1), pp. 114.

- Rajagopal, K. J.-t. B. D. V. B. J. \&. S. P., 2012. Understanding personal learning networks: Their structure, content and the networking skills needed to optimally use them. Open Universiteit: First Monday, 17(1).

- $\quad$ Reddick, R. J., 2015. Of Feral Faculty and Magisterial Mowglis: The Domestication of Junior Faculty. New Directions for Higher Education, 2015(171), pp. 43-51.

- Rhode, D., 2017. Leadership in Law. Standford Law Review, 69(6), pp. 16031666.
- $\quad$ Simmons, J., n.d.. 9 Companies with solid mentorship programs. [Online]

Available at: https://www.monster.com/careeradvice/article/9-companies-withsolid-mentorship-programs-0816

- $\quad$ Starcevich, M. M., n.d.. Coach, Mentor: Is there a Difference? [Online] Available at: http://www.coachingandmentoring.co m/Articles/mentoring.html

- Vance, M., 2016. The Importance of Mentoring for Higher Ed Leadership. [Online] Available at: https://www.higheredjobs.com/article s/articleDisplay.cfm?ID $=1077$

- Wenzel, F., 2015. Developing Leaders. Military Review, July-August, 95(4), pp. 33-41.

- Williams, F. S. E. S. T. D. E. a. S. M., 2018. New Nurse Graduate Residency Mentoring: A Retrospective CrossSectional Research Study Nurse residency programs. Nursing Economic\$, 1 May, 36(3), pp. 121-127. 